Ravi, R.,Lædre, O., Fosse, R., Vaidyanathan, K., and Svalestuen, F. (2018). "The Last Planner System: Comparing Indian and Norwegian Approaches." In: Proc. $26^{\text {th }}$ Annual Conference of the International. Group for Lean Construction (IGLC), González, V.A. (ed.), Chennai, India, pp. 381-391. DOI: doi.org/10.24928/2018/0421. Available at: www.iglc.net.

\title{
THE LAST PLANNER SYSTEM: COMPARING INDIAN AND NORWEGIAN APPROACHES
}

\author{
Ramakrishnan Ravi', Ola Lædre'2, Roar Fosse ${ }^{3}$, \\ Kalyan Vaidyanathan ${ }^{4}$, Fredrik Svalestuen ${ }^{5}$
}

\begin{abstract}
Construction projects around the world currently use the Last planner system (LPS) with different approaches. In this paper, we compare the Indian and Norwegian industry because of their contrasting cultural settings, in order to gather experiences and formulate possible improvements to their LPS approaches. A general literature study regarding LPS and its components was carried out. Data from two cases in India and six cases in Norway were collected with the help of three case specific and five general interviews.

The study revealed similarities in scheduling and planning, root cause and constraint analysis, PPC measurements (daily and weekly) during the meetings. The major difference was that the Indian companies use LPS as a problem solving technique in the middle of the project and the Norwegian companies use it proactively as a part of their system. A major conclusion drawn in the paper is that the participants felt more ownership to the schedule and the activities after the introduction of LPS. It became a promise of what they could do, rather than an order from the manager.
\end{abstract}

\section{KEYWORDS}

Last planner system, Hofstede Analysis, People, Culture and Change

\section{INTRODUCTION}

Poor project performance in construction is often related to factors like uncertainty or variability in workflow (Howell and Ballard, 1998; Ballard and Howell, 2003). The Last Planner System (LPS) was developed in order to reduce those uncertainties in the workflow (Ballard and Howell, 2003). According to Mossman (2014, pp.1-5), LPS intends

1 MSc Candidate, NTNU - Norwegian University of Science and Technology, Trondheim, Norway, +47 96711277, ramakrir@stud.ntnu.no

2 Associate Professor, Dept. of Civil and Transport Engineering, NTNU Norwegian University of Science and Technology, Trondheim, Norway, +47 91189 938, ola.ladre@ntnu.no

3 Regional Manager, Lean Construction, Skanska, Oslo, Norway, +4793444588, roar.fosse@ skanska.no

4 CEO, Nadhi Information Technologies, 22 Venkatraman Street, T. Nagar, Chennai 600017. India; Phone: +9197910 41483; kalyanv@ nadhi.in

5 Ph.D. Candidate, NTNU - Norwegian University of Science and Technology, Trondheim, Norway/Design Manager, Veidekke Entreprenør AS, +47 98673 172, fredrik.svalestuen@ntnu.no 
to improve the reliability and predictability of the plans used for construction activities during the implementation stage through an integrated approach. It has proven benefit on project performance for more than 20 years in multiple countries, across building construction, heavy civil engineering construction, highway and infrastructure projects, including ship building and pit mining (Liu and Ballard, 2008; Ballard, 1993; Ballard and Howell 2003; Alarcón et al. 2008). Engebø et al. 2017found that, adjusted for the number of inhabitants, the interest for Lean Construction is much higher in Norway than in India. This correlates with previous experience of the first author from both the Indian and Norwegian construction industry and is a key motivation to compare the implementation of the last planner system between India and Norway, respectively.

In the following, the paper presents the main results from a literature review. Then a short explanation of the applied research methods is given. The findings and discussion part follows this, before the consequences of cultural differences between India and Norway are analysed. Finally, the paper presents conclusions on the three research questions.

\section{LITERATURE REVIEW}

The Last Planner System (LPS) focuses on planning and production control where the different components include master schedule, phase planning, look ahead (make-ready) planning, production planning, production management and learning (Ballard and Howell, 2003; Ballard, 2000; Mossman, 2014). Anextensive study from Daniel et al. (2015)shows the different components of LPS used in 57 case studies across 16 different nations(including seven from Norway and one from India). Figure 1 gives an overview of the components that are frequently used. This case study has been used to identify the LPS components that are used around the world and it would be a good base to compare these with the actual components that are used in the Indian and Norwegian projects.

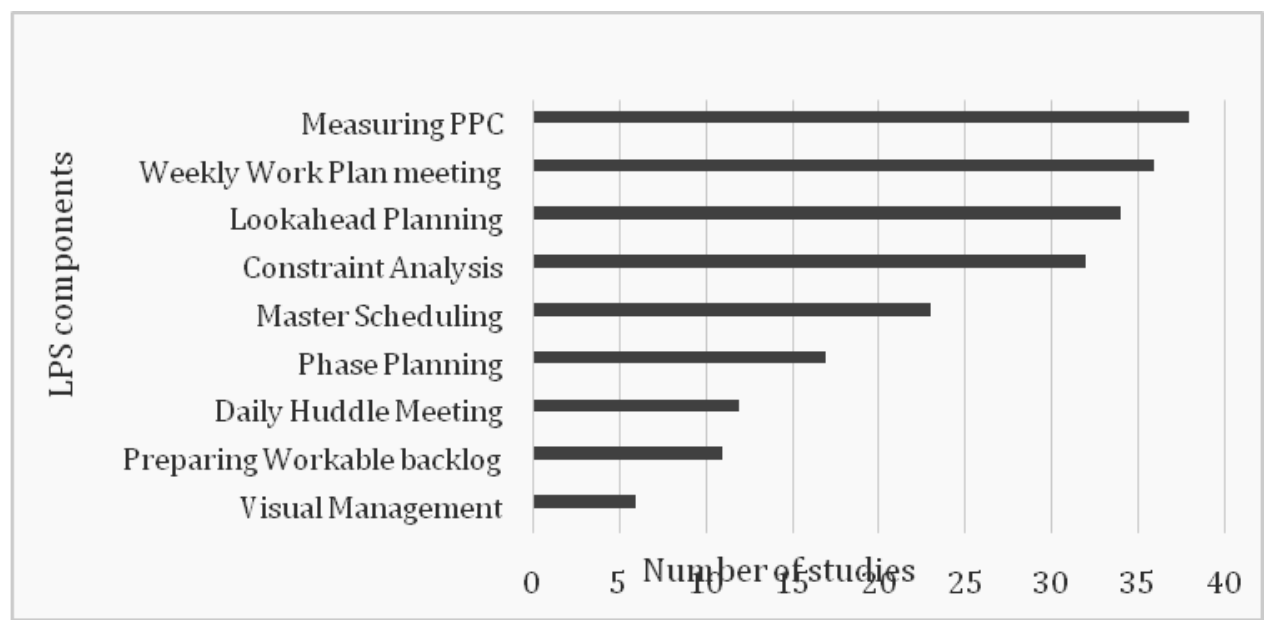

Figure 1: Some of the LPS components used in 57 cases (based on Daniel et al.2015)

A study from Johansen and Porter (2003) reveals that cultural barriers like attitude to work have a say when LPS is implemented. In an attempt to get a better insight in this 
statement, the authors have studied a cultural assessment field called Hofstede's cultural dimensions theory. Hofstede is perhaps more known in fields such as sociology and psychology than engineering, but the authors argue that with culture and people being such a strong proponent of Lean practices, such cultural analysis tools could provide valuable insights into factors of success or failure of certain practices in certain cultural conditions.To help understand the difference between the cultures of countries, such as Norway and India, Hofstede looks to score them within six so-called cultural dimensions. First, Power Distance is "the extent to which a society accepts the fact that distribution of power in institutions and organizations is unequal" (Hofstede, 1980b, p. 45).Individualism is "the degree to which people in a country prefer to act as individuals rather than being a member of a group" (Hofstede, 1994, p. 6).Masculinity is "the extent to which the dominant values in a society are related to their assertiveness, acquisition of money and things" (Hofstede, 1980b, p. 46). Uncertainty avoidance is "the extent to which a society tolerates ambiguous situations and tries to avoid these situations by establishing more formal rules and believing in absolute truths" (Hofstede, 1980b, p. 45).Long-term orientation is "the ability of a society to connect the past with the current and future challenges" (Hofstede, G., 2011).Finally, Indulgence is "the extent to which a society allows relatively free gratification of basic human desires related to enjoying life and having fun." (Hofstede, G., 2011). Hofstede's cultural index has some limitations. For example, it presumes the whole population is equal, but not all sub-cultures and individuals necessarily fit into it.Nevertheless, the data collected is important as long as the context and content of the questions is phrased in the right manner (Clearlycultural.com, 2018).Critics claim that this model does not capture the complete phenomenon, as culture has more than six dimensions (Chao \& Moon, 2005).

\section{RESEARCH METHODOLOGY}

The research questions in this paper are:

- How is the Last Planner System implemented in India and Norway?

- What are experiences gained with implementation in both the countries?

- What are potential improvements that could be made to LPS considering the cultural aspects?

A literature search for LPS theories and its components was carried in research databases, both with keywords and by using backwards snowballing (Wee and Banister 2016). This study has helped in identifying LPS components that are in theory and whether the same set of components are being used in the case study projects.

Two case studies from India have been studied, namely one Marine jetty project and one residential project. Nadhi Information Technologies, a consultant company facilitating contractors in India to implement LPS in their projects and having a lot of experience in implementing LPS in India, provided both these cases. Six residential, commercial and office building projects from Norway were also studied. Since, contractors in Norway have a longer history of Lean practices and a project management system inbuilt with LPS, more number of projects could be studied from two of the major contractors in Norway. Three cases were 
from Skanska and three were from Veidekke Entreprenør AS. The projects range from residential, commercial and office building projects. The lead author conducted a document study of documents received from the respondents. The Indian documents were mainly project details(location, project cost, type of project etc.), changes caused in the project by implementing LPS, PPC measurements, productivity reports from site, cycle time charts etc. The Norwegian documents were mainly handbooks explaining their LPS implementation. The case studies were based on semi-structured open-ended interviews. The respondents were sorted in two categories, namely case specific respondents and generic respondents. In order to avoid bias, the respondents answered identical questions from an interview guide. By interviewing construction managers and LPS experts, different perspectives were accounted for. In total, four interviews were conducted in India and two in Norway.

With the help of the project data collected (changes in the LPS metrics) and the interviews with the lean experts (the extent to which different LPS components were implemented in the site), cross analysis was done. These findings were analysed with the help of Hofstede's six cultural dimensions to reveal the cultural enablers and roadblocks for implementation of LPS in both countries.

\section{FINDINGS AND DISCUSSION}

Since it was difficult for the authors to give a detailed explanation about each case and each interview, the information presented in the section below is an amalgamation of both the sources of data.

\section{INDIA}

The Institute for Lean Construction Excellence, India (ILCE - http://www.ilce.in) has been creating a basic awareness of lean amongst both mid managers and top executives over the past few years through seminars, workshops, education and running local chapters. There are high expectations on the results from lean and what it can achieve for projects (in terms or bringing delayed projects back on track and eliminating cost overruns). From the two case studies and the interviews general experience, a typical approach to implementing LPS in India is as follows: The need for LPS is felt a few months into project execution, when conventional approach has led to delays. There is pressure to bring the project(s) back on track. A third party lean consultant is hired to introduce the lean construction techniques (including LPS), does the site observations to understand the current condition of the project, report the "as-is" situation and a "to-be" intervention plan to the higher management. The Lean initiative is often kicked off at the site with awareness workshops and possibly simulation games (e.g. the parade of trade game) (Tommelein et al.1999).Then, the expectations from the site going forward is set by the third party consultant.

A phase schedule based on the contractual milestones is prepared, which is then broken down into a rolling 6-week look ahead schedule, weekly plans and daily plans as part of the weekly planning process. A weekly work planning meeting is held in order to plan the work that has to be executed in the upcoming week. The meeting is also used to discuss top delay reasons of the PPC and potential improvements. Daily Standup meetings of maximum 20 minutes are conducted to gather PPC and delay reasons, as well 
as discussing shared tools and equipment for the next day. There is a strong emphasis for crews not to focus just on completing their workload, but to generate adequate finished work for the trade behind them, to ensure adequate flow of work at a reliable pace. Since LPS is often implemented in the middle of Indian projects, there is often inadequate time and focus on training up-front to properly establish the necessary culture and mindset. This often leads to participants initially struggling with common LPS skills such as clearly expressing what they need from each other, formulating well-described tasks, properly matching workload with needed labor etc. However, with time an increased schedule reliability and overall efficiency of the execution team have been observed in the studied cases.

There are also organizational challenges; for instance, if the lean consultant is hired by the contractors, the client might not endorse lean and understand the need for efforts such as removing constraints as part of the look ahead (make ready) process. This is partially because owners want the freedom to make changes until the end and partly because they also lack awareness of the lean process. There are also socio-cultural challenges, such as entry-level field engineers finding it difficult to say "no" to what they perceive as unrealistic requests from their managers. Even worse, they might be forced to give commitments that satisfy the expectations of management irrespective of the actual situation. One reason behind this, we postulate, is the Indian education system where students from their childhood are taught to respect elders and teachers (hierarchy) without asking questions. Therefore, lean consultants have to "unlearn" this habit to create an environment of freedom to say no.

Despite the mentioned challenges, the interviews identified some clear pockets of success in implementing LPS. One of the projects experienced a reduction of cycle time by around $40 \%$ (Vaidyanathan 2015). In the second case study also, the contractor experienced a $45 \%$ reduction in completion of coping beams in civil works. PPC on daily basis increased from $40 \%$ to $91 \%$ and PPC on weekly basis increased from $36 \%$ to $82 \%$.The increase in PPC was due to the increased awareness of non-completion by introducing a rigorous application of Value stream mapping of reasons for those noncompletions. A more significant intangible benefit was the recognition from the Client who noted that the contractor's ability to make and keep commitments had significantly improved in the six months after the adoption of LPS (Madhusudhanan 2017).

\section{NORWAY}

The Last Planner System seems to have entered the Norwegian industry around mid2000s, with predominantly two large contractors incorporating it into their planning and control systems; Veidekke and Skanska (Kalsaas et al., 2009).Two major contractors in Norway - Veidekke Entreprenør and Skanska Norway - have LPS built into their project management systems.One reason of analyzing the LPS strategies of two different companies is to figure out the degree of similarity between them and the strategical differences in their system keeping the Norwegian culture in mind. These two contractors have a similar conceptualization and implementation of LPS, expect for the meeting structure. Employees get central training in LPS, as well as project-specific support during execution. Their planning hierarchies follow the theoretical prescriptions for LPS 
with master and phase scheduling, look ahead planning, making commitments, weekly and daily planning, tracking of progress and learning.

In terms of meeting structure, Veidekke has four weekly progress meeting. The first one focusses on workforce and subcontractors plan their weekly work plan. They have another meeting where the foremen and subcontractors make their 2-4 week look ahead plan. In the third meeting, the site manager meets the project manager to discuss the 5-9 week look ahead schedule. In the fourth meeting, all subcontractors meet the foremen to discuss the work done that week by measuring the PPC and prepare work for the next week. For making work ready, they have an MS Project schedule linking every activity to each of the seven pre-requisites and a YES/NO column, whereas only activities with YES on all seven are ready to be included on the weekly work plan. If there is a problem regarding any of the pre-requisites, someone is made responsible for removing the constraints by Friday of that week. Incomplete activities in the PPC review are moved to the next week as a part of workable backlog. Skanska usually have two progress meetings per week for production work. One meeting involving participants from all the trades and one is for the foremen to coordinate. In addition, they have a daily job briefing, where each crew goes over their upcoming daily tasks, coordinates against other trades, material deliveries etc. The progress of the design schedule is quite thoroughly reviewed as part of the weekly Last Planner process described in Fosse \& Ballard (2016). If needed, Skanska teams add other progress meetings, and often also a PPD (production-procurement-design) coordination meeting for the in-house managers. Skanska's most of the projects plan their on-site activities location-based in their pull-planning sessions as a part of LPS in their system.

LPS is out of many project participants' (especially the sub contractors) comfort zones compared to traditional planning methodologies. Many are used to having schedules created just for their trade and working in silos, without the rigorous coordination between trades and phases as LPS often promotes. From the interviews with the Norwegian practitioners, it was identified that there lies a challenge in managing people on different hierarchical levels looking at different time frames. For example, a manager (the leader) who looks two to four weeks ahead can disrupt the planning ability of a foreman who is used to look at (and good at coordinating) one week ahead.

\section{LPS IMPLEMENTATION MATURITY MATRIX}

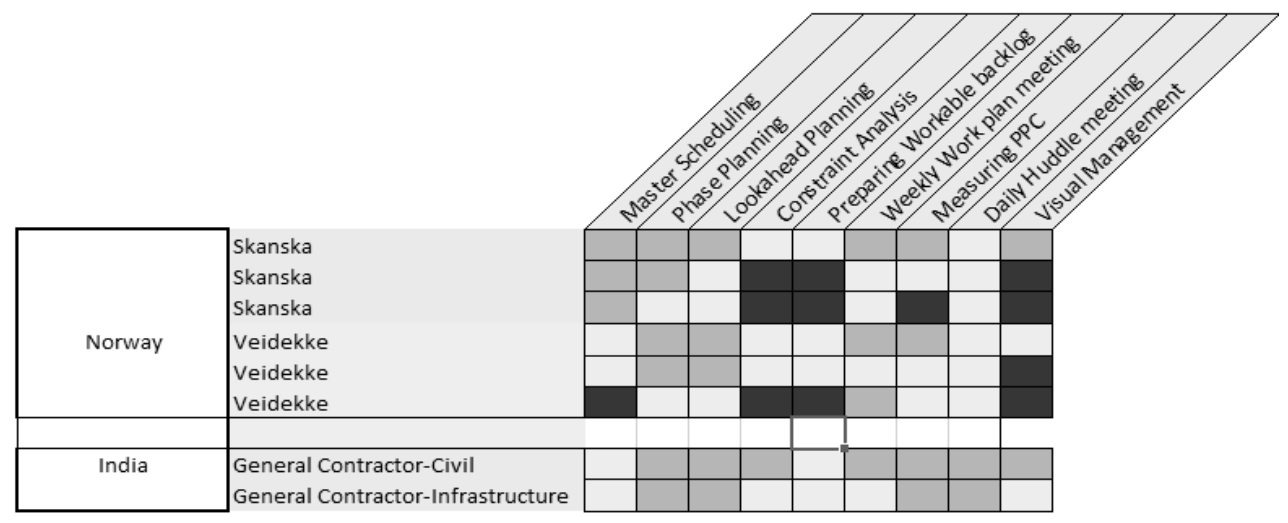


Figure 2: LPS Implementation Maturity Matrix

With the available case studies and interviews from the Indian and Norwegian side, an attempt has been made to summarize the implementation grade of the LPS components in the investigated cases from Norway and India. The colors presented in Figure 2 represent the degree of implementation and these scores were given by the authors based on findings from the interviews and the case studies and these scores are subjective in nature. Green denotes that the practical implementation is similar to LPS theory, yellow to some degree or acceptable substitute practices and red denotes not corresponding at all. An important learning from the matrix is that the Norwegian projects, although having LPS incorporated in their systems, only use selected components on many projects. The Indian projects on the other hand, use almost all LPS components as described in theory, irrespective of a positive or negative outcome. The lean experts of Veidekke and Skanska experienced project success despite poor LPS implementation, as well as project failure despite successful LPS implementation. Therefore, it is difficult to directly correlate LPS implementation with project success based on LPS metrics.

\section{HOFSTEDE ANALYSIS RESULTS}

The Hofstede values of Norway and India are given in Figure 3, and they will be used to analyze the cultural reasons behind the usage of LPS components. These scores have been obtained from the Hofstede's cultural dimension scores for different nations and the website link for checking the scores has been provided in the references.

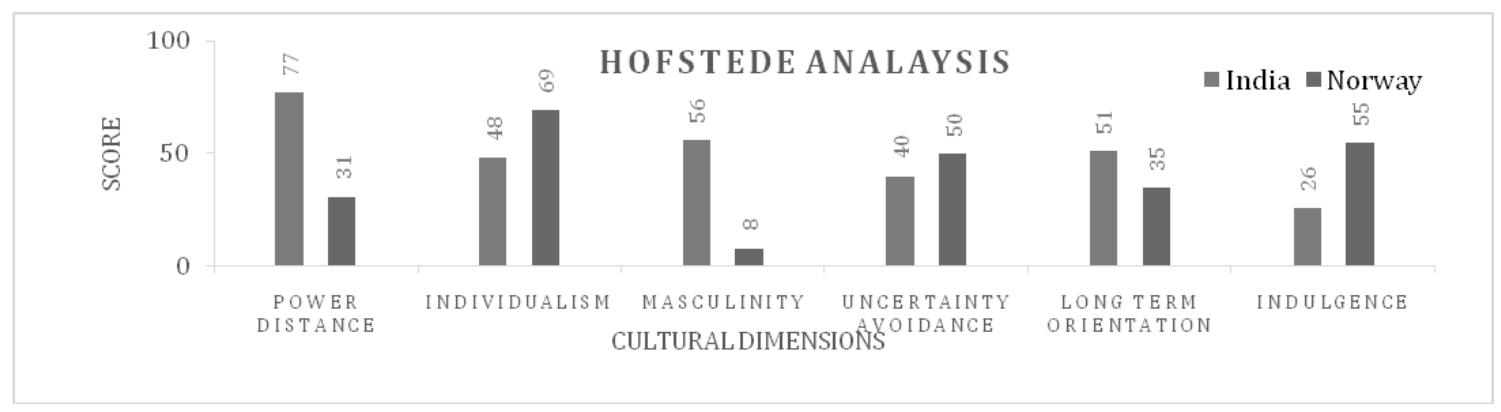

Figure 3: Hofstede Analysis results for India and Norway (Hofstede Insights, 2018)

Power Distance, India 77, Norway 31. An example would be socio-cultural challenges presented under the Indian side. This could indicate that Norwegians have a flat hierarchical structure, increasing their ability to say "no", which seems like a very important premise for reliable promises. This might explain why Norwegian contractors have LPS incorporated into their systems of standard planning practices.

Individualism, India 48, Norway 69. This factor relates to how the two countries see it natural to act as a single person or as a team. One way of interpreting this is that it should be more natural in India to appreciate LPS as a way of working as teams. An example would be the increase in the PPC shown in the Indian case studies, as it increased when people started to work more as a team, not just achieving individual goals. 
Masculinity, India 56, Norway 8. This factor could be related to how decisions are made. Indians have assertive decision-making power within a few individuals of a group, while Norwegians might rather listen to all opinions before making collective decisions. This may cause that the pull-planning sessions in Norway are better to coordinate trades involved than those in India.

Uncertainty avoidance, India 40, Norway 50. This factor however could be related to how important it is for the teams to make work ready in a timely manner rather than accepting that not everything is in place before execution of work and making-do. Another example would be organizational challenges presented under the Indian side, where the owners hesitate to take responsibility on the work of Lean experts.

Long-term orientation, India 51, Norway 35. This indicates a better pre-condition for lookahead-planning in India than Norway. On the other hand, it might also indicate that India is more culturally prone to plan construction projects too much in detail too early, rather than following the LPS principle of planning to the right level of detail to the right time and accepting that things don't go as planned, but rather be able to change accordingly in an agile way.

Indulgence, India 26, Norway 55. This factor could be related to the social processes of LPS. Norwegians might be more comfortable with the informal tone and inter-personal communication often related to several components of LPS.

\section{CONCLUSION AND RECOMMENDATION:}

Looking at implementation experiences of the practitioners from the Indian and Norwegian industry, the need for cultural change to adjust to a new process such as LPS might take more time than anticipated by lean advocates. In terms of implementation, the findings from the interviews seem to correlate well with the Hofstede analysis of the two countries. Indian workers and entry-level engineers might struggle with saying "no" to their manager rather than giving a reliable promise because of the power distance. Norwegian contractors might have challenges coordinating people, as they can be individualistic in nature. Masculinity might lead to Indian project teams having a few strong individuals making decisions on behalf of the team, while a Norwegian team depends on group decisions. Furthermore, Hofstede's six cultural dimensions have been helpful in explaining the experiences related to different LPS components. For instance, look ahead planning should correlate with the ability to think long-term, constraint analysis should correlate with the ability to accept uncertainty. Based on differences between the Norwegian and Indian cultures, the potential improvements that could be made in order to improve the process that could involve change in their cultural ethos include:

- Norway: Use a Bottom up approach for LPS on the Norwegian side, where the subcontractors and foreman can be taught to plan for the next day in the beginning and a step by step increase to asking them to do the look ahead plan for 6-8 weeks. Indian counterparts could try LPS at two levels (learning from Norway): a short-term one that only involves coordination among contractors 
and a medium-term one that involves owners and contractors coordinating design and procurement.

- Norway: For the Norwegian counterparts to try other aspects of LPS and see if that leads to improved reliability and efficiency of project delivery. Particularly, the daily stand up meetings and value stream mapping is something they could try.

- India: The execution engineer, in India, or the person responsible for the activity should be given the freedom to say "No", so that he can make reliable commitments. Owners should not involve in disrupting the planning ability of the contractors in the Indian side; they should be less "masculine" about it in the interest of the project. Regarding the Norwegian side, the foreman who has to look ahead plan for 6-8 week ensure that their actions do not disrupt the 1-2 week plan of the sub-contractor.

- India: Clients and management (especially in cultures such as India) should try to be less "masculine" and empower entry-level field engineers to have opinions. Subcontractors and foremen can be gradually empowered to increase their planning capabilities and responsibilities. Especially if just asked to do short-term daily planning, one could increase responsibility to do look ahead planning and have more impact on identifying and handling constraints.

All in all, both sides have something to learn from each other's successes (or lack thereof). And both sides have some room to improve their cultural baggage to improve the adoption of the principles of LPS and achieve better success in project delivery through the use of LPS. In general, the Lean Construction community should have even more discussions about the cultural pre-conditions of the countries, companies and project organizations where Lean Construction practices are implemented. There is a need for improved insight of what factors that enable successful adoption.

\section{REFERENCES}

Alarcón, L. F., Diethelm, S., Rojo, O., and Calderón, R. (2008). “Assessing the impacts of implementing lean construction." Revista Ingeniería de Construcción, 23, 26-33.

Ballard, G., 1993. Lean Construction and EPC Performance Improvement. In: L.F. Alarcón, ed. Lean Construction. Rotterdam, Netherlands: A.A. Balkema Publishers.

Ballard, G., 1997, July. Lookahead planning: the missing link in production control. In Proc. 5 th Annl. Conf. Intl. Group for Lean Constr.

Ballard, G. and Howell, G., 1998. Shielding Production: Essential Step in Production Control. ASCE, J. Constr. Eng. Manage,. 124(1), pp. 11-17.

Ballard, H.G., 2000. The last planner system of production control (Doctoral dissertation, University of Birmingham).

Ballard, G. and Howell, G., 2003, July. An update on last planner. In Proc. 11 th Ann. Conf. of the Int'l. Group for Lean Constr (pp. 22-24). 
Ballard, G., Hamzeh, F.R. and Tommelein, I.D., 2007. The Last Planner Production Workbook-Improving Reliability in Planning and Workflow. San Francisco, CA:: Lean Construction Institute.

Ballard, G. and Tommelein, I., 2016. Current process benchmark for the Last Planner® System. Lean Construction Journal, pp.57-89.

Chao, G. and Moon, H. (2005). "The cultural Mosaic: A Metatheory for Understanding the Complexity of Culture. " Journal of Applied Psychology, vol 90 no 6 1128-1140.+

Clearlycultural.com. (2018). Geert Hofstede cultural dimensions | Clearly Cultural. [online] Available at: http://www.clearlycultural.com/geert-hofstede-culturaldimensions/ [Accessed 11 Apr. 2018].

Chao, G. and Moon, H. (2005). "The cultural Mosaic: A Metatheory for Understanding the Complexity of Culture. " Journal of Applied Psychology, vol 90 no 6 1128-1140.

Daniel, E.I., Pasquire, C. and Dickens, G., 2015. Exploring the implementation of the Last Planner® System through IGLC community: twenty one years of experience. In: Proc. 23rd Ann. Conf. of the Int'l. Group for Lean Construction. Perth, Australia, July 29-31, pp. 153-162

Engebø, A. , Drevland, F. , Lohne, J. , Shkmot, N. \& Lædre, O. 2017, 'Geographical Distribution of Interest and Publications on Lean Construction' In:, 25th Annual Conference of the International Group for Lean Construction. Heraklion, Greece, 9-12 Jul 2017. pp 285-292

Fosse, R. \& Ballard, G. 2016, 'Lean Design Management in Practice With the Last Planner System' In:, 24th Annual Conference of the International Group for Lean Construction. Boston, USA, 20-22 Jul 2016.

Hofstede, G., 2011. Dimensionalizing cultures: The Hofstede model in context. Online readings in psychology and culture, $2(1)$, p.8.

Hofstede, G. (1980b). Motivation, leadership, and organization: Do American theories apply abroad? Organizational Dynamics, 9, 42-63.

Hofstede, G. (1994). Management scientists are human. Management Science, 40, 4-14.

Hofstede Insights. (2018). Country Comparison - Hofstede Insights. [Online] Available at: https://www.hofstede-insights.com/country-comparison/india,norway/[Accessed5 Mar. 2018].

Johansen, E. and Porter, G., 2003. An Experience of Introducing Last Planner into a UK Construction. In: Proc. 11th Ann. Conf. of the Int'l Group for Lean Construction, Virginia, USA, July 22-24.

Kalsaas, B.T., Skaar, J. and Thorstensen, R.T., 2009. Implementation of Last Planner in a medium-sized construction site. In IGLC (Vol. 15, p. 2009).

Liu, M. and Ballard, G., 2008. "Improving Labour Productivity through Production Control". In: Proc. 11th Ann. Conf. of the Int'1 Group for Lean Construction, Blacksburg, Virginia, July 22-24.

Madhusudanan V. (2017). "Learnings from Implementation of Last Planner in a Marine Infrastructure Project in South India", Proc. of $2^{\text {nd }}$ Indian Lean Construction Conference, Chennai, India. July 28 \& 29, 2017

Mossman, A. (2014). "Last Planner: $5+1$ crucial \& collaborative conversations for predictable design \& construction delivery". The Change Business Ltd. 
Vaidyanathan, K. (2015). "Learnings from Application of Last Planner in a Residential Project", Proc. of $1^{\text {st }}$ Indian Lean Construction Conference, Mumbai, India. February $5-7,2015$.

Tommelein, I.D., Riley, D.R. and Howell, G.A., 1999. Parade game: Impact of work flow variability on trade performance. Journal of construction engineering and management, 125(5), pp.304-310.

Wee, Bert Van and David Banister (2016). How to Write a Literature Review Paper?" In: Transport Reviews 36.2, pp. 278-288. 